\title{
Effect of COVID-19 on ETF and index efficiency: evidence from an entropy-based analysis
}

\author{
Kunal Saha ${ }^{1,2}$ (D) Vinodh Madhavan ${ }^{3}$ (D) . G. R. Chandrashekhar ${ }^{4}$
}

Accepted: 13 November 2021 /Published online: 7 January 2022

(c) Academy of Economics and Finance 2021

\begin{abstract}
We examine the informational efficiency of domestic equity ETFs vis-a-vis their underlying market indices during the COVID-19 pandemic. To do so, we employ a multiscale entropy-based methodology. Our findings indicate that the informational efficiency of all ETFs as well as the indices fall sharply during the COVID induced market crash in February-March 2020. Having said so, we find disproportionate deterioration in market efficiency of ETFs and indices pertaining to USA and Canada as compared to those of China, Hong Kong and Taiwan. Interestingly, ETFs and indices pertaining to certain developed markets were found to be less efficient than their emerging market counterparts even during the pre-covid timeline. Lastly, there is a discernible difference between the efficiency of ETFs vis-a-vis their underlying indices. These findings should nudge investors to exercise caution while dealing with ETFs, for domestic ETFs do not exactly mimic the dynamics of their underlying indices.
\end{abstract}

Keywords COVID-19 · Entropy $\cdot$ Exchange traded funds $\cdot$ Adaptive market hypothesis

JEL classification: G01 · G14 · G15

\section{Background}

The dynamics of market efficiency during financial crises has been one of the primary focus areas of financial research. The discourse on market efficiency is heavily influenced by the Efficient Market Hypothesis, which postulates that asset prices

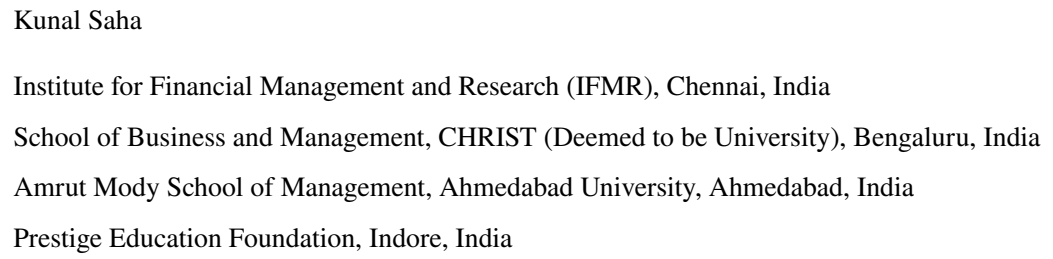


should follow a random walk (Fama 1965). The rise in popularity of index based Exchange Traded Funds (ETFs) over the last decade, may be attributed to the belief that markets are indeed efficient and hence active investments strategies cannot consistently beat the market. ETFs also offer additional benefits over mutual funds which include lower expense ratio and reduced tax incidence.

Studies that examine ETF efficiency in the context of Efficient Market Hypothesis usually employ traditional econometric methodologies such as regression and cointegration (Xu et al. 2017, 2019; Huang et al. 2021). However, irregularities such as long memory, self-similarity and other non-linear phenomenon have also been reported in financial time series data of ETFs and equity indices (Zhu and Bao 2019; Saha et al. 2020; Caporale et al. 2020).

The current COVID-19 pandemic adversely affected markets across the globe. It has been earlier observed that financial crises can affect different markets to varying degrees (Lim et al. 2008). This study contributes to the literature on market efficiency in the following ways. First, we examine the level of informational efficiency of domestic ETFs and their respective underlying equity indices using an entropy based methodology. In doing so, we compare the degree of efficiency of developed vis-a-vis emerging market ETFs and underlying indices. Second, we examine the impact of covid-19 crisis on the informational efficiency of ETFs and underlying indices. While prior studies have used entropy based measures to examine efficiency across different assets (Alvarez-Ramirez et al. 2012; Ortiz-Cruz et al. 2012), we employ a recently proposed "refined composite multiscale fuzzy entropy" (RCMFE) algorithm that is more accurate and stable, especially for shorter temporal scales (Azami et al. 2017).

\section{Methodology}

Entropy measures the extent of disorder in a system. In the context of information theory, higher values of entropy for a time series process corresponds to higher levels of efficiency (Gulko 1999). A drop in market prices induced by a market crash creates a trend, that reduces entropy and thereby, informational efficiency. The first step in this analysis is to calculate the entropy of the dataset using the RCMFE method (Azami et al. 2017). Next, we use the informational efficiency index as proposed by Wang and Wang (2021). A brief description is provided here.

\subsection{Refined composite multiscale fuzzy entropy}

From a time series $y=y_{1}, y_{2}, \ldots, y_{N}$, a de-meaned vector is created as

$$
\begin{aligned}
U_{t}^{m} & =y_{t}, y_{t+1}, \ldots, y_{t+m-1}-y_{0 t}, \text { where } \\
y_{0 t} & =\sum_{j=0}^{m-1} \frac{y_{t+j}}{m} \text { for } t=1,2, \ldots, N-(m-1)
\end{aligned}
$$


Here, $m$ denotes the embedding dimensions which define the count of samples in every vector. The separation between two vectors is given by:

$$
d_{t_{1} t_{2}}=d\left[U_{t_{1}}^{m}, U_{t_{2}}^{m}\right]=\max \left\{\left|U_{t_{1}+k}^{m}-U_{t_{2}+k}^{m}\right|: k \in[0, m-1] \& t_{1} \neq t_{2}\right\}
$$

When this distance is lesser than a given tolerance $r$, a match occurs. This degree of similarity is measured by the

$$
D_{t_{1} t_{2}}=\exp \left(-\left(d_{t_{1} t_{2}}\right)^{n} / r\right)
$$

for the level $r$ and entropy power $n$. Next, the fuzzy entropy of the time series $(y)$ is estimated as:

$$
\mathrm{FE}(y, m, n, r)=-\ln \left(\frac{\phi^{m+1}}{\phi^{m}}\right)
$$

where the function $\phi^{m}$ is given by

$$
\phi^{m}(y, n, r)=\frac{1}{N-m} \sum_{t_{1}=1}^{N-m} \frac{1}{N-m-1} \sum_{t_{1}=1, t_{1} \neq t_{2}}^{N-m} D_{t_{1} t_{2}}
$$

Further, the RCMFE measures the entropy at various time scales that are used to arrive at the multi-scale market efficiency. These can be understood as being daily, weekly or monthly. For these, a coarse-graining procedure is employed to extract variations at all scales.

For every time scale factor $\tau$, separate coarse-grained series are created as $z_{u}^{(\tau)} \mid(u=1, \ldots, \tau)=\left\{y_{u, 1}^{(\tau)}, y_{u, 1}^{(\tau)}, \ldots\right\}$, with mean as

$$
\mu_{y_{u, j}(\tau)}=\frac{\sum_{b=u+\tau(j-1)}^{u+\tau j-1} y_{b}}{\tau}
$$

RCMFE improves upon previous measures of entropy by extracting more information from the data since it allows for overlapping windows at every $\tau$. This is implemented by calculating fuzzy entropy for all time scales and then averaged over $u=1, \ldots, \tau$ to get average $\bar{\phi}_{\tau}^{m}$ and $\bar{\phi}_{\tau}^{m+1}$. Subsequently, the RCMFE is calculated as:

$$
\operatorname{RCMFE}(y, \tau, m, n, r)=-\ln \left(\frac{\bar{\phi}_{\tau}^{m+1}}{\bar{\phi}_{\tau}^{m}}\right)
$$

\subsection{Index of informational market efficiency}

Asset returns should follow Gaussian white noise in a completely efficient market. Hence, the index of informational market efficiency $\left[I_{I M E}(\tau)\right]$ is calculated for all time scales $\tau$ as: 
Table 1 List of ETFs and Equity Indices considered for this study

\begin{tabular}{llll}
\hline Region & Domestic ETF & Equity Index & Inception Date (ETF) \\
\hline Australia & Vanguard Australian Shares Index ETF & S\&P ASX 300 Index & May 08, 2009 \\
Brazil & iShares Ibovespa ETF & IBOV Index & Dec 02, 2008 \\
Canada & iShares S\&P/TSX 60 Index ETF & S\&P/TSX 60 Index & Sep 28, 1999 \\
China & China 50 ETF & SSE 50 A Share Index & Feb 23, 2005 \\
Eurozone & Xtrackers Euro Stoxx 50 UCITS ETF & Euro Stoxx 50 Index & Aug 27, 2008 \\
France & Lyxor CAC40 DR-D-EUR ETF & CAC40 Index & Jan 22, 2001 \\
Germany & iShares Core DAX UCITS ETF & DAX Index & Jan 03, 2001 \\
Hong Kong & Tracker Fund of Hong Kong Ltd & Hang Seng Index & Nov 12, 1999 \\
India & SBI NIFTY50 ETF & NIFTY Index & Jul 27, 2015 \\
Japan & Next TOPIX ETF & TOPIX Index & Jul 13, 2001 \\
New Zealand & Smartshares NZ Top 50 ETF & NZSX 50 Index & Dec 10, 2004 \\
South Korea & Samsung Kodex 200 Securities ETF & KOSPI200 Index & Oct 14, 2002 \\
Taiwan & Yuanta/P-shares Taiwan Top 50 ETF & TW50 Index & Jun 25, 2003 \\
UK & iShares Core FTSE 100 UCITS ETF & FTSE100 Index & Apr 27, 2000 \\
United States & SPDR S\&P 500 ETF Trust & S\&P 500 Index & Jan 22, 1993 \\
\hline
\end{tabular}

$$
I_{I M E}(\tau)=\frac{\operatorname{RCMFE}(y, \tau, m, n, r)}{\beta(\tau)} \times 100 \%
$$

with $\beta(\tau)$ depicting the upper bound entropy of 5000 Monte Carlo simulations of Gaussian white noise samples. For $I_{I M E}(\tau)<100 \%$, the asset can be interpreted as partially or fractionally efficient.

\section{Data}

Table 1 provides the names of the domestic equity ETFs and their respective underlying indices that are considered for this study. We retrieve log returns of daily closing prices of each ETF and its index from January 2018 to April 2021 from Bloomberg. For this study, we chose the largest (by assets under management) domestic ETFs from various markets which fully replicate their indices without derivatives or leverage. This is done to prevent confounding factors at the time of interpreting results.

At the outset, we check the descriptive statistics of the log returns time series data of ETFs and their indices. We use the descriptive statistics data to compare the change from the pre-crash period (Jan 2018 to Jan 2020) to post-crash period (Apr 2020 to Apr 2021). We exclude the period of the crash from February to March 2020 since the volatility was very high during this period. However, even after removing these months of date, we can see that the descriptive statistics, especially the skewness and kurtosis changed markedly in the post crash period compared to the pre-crash period. The following Table 2 shows the details. 
Table 2 Descriptive Statistics of $\log$ returns of ETFs and their Indices (Pre and post crash)

\begin{tabular}{|c|c|c|c|c|c|c|c|c|c|}
\hline \multirow[t]{2}{*}{ Region } & \multirow[t]{2}{*}{ Instrument } & \multicolumn{4}{|c|}{ Prior to Feb-March 2020 crash } & \multicolumn{4}{|c|}{ Post Feb-March 2020 crash } \\
\hline & & Mean & Std. Dev & Skewness & Kurtosis & Mean & Std. Dev & Skewness & Kurtosis \\
\hline \multirow[t]{2}{*}{ Australia } & ETF & 0.000 & 0.007 & -0.981 & 2.705 & 0.001 & 0.011 & 0.037 & 1.941 \\
\hline & Index & 0.000 & 0.007 & -0.964 & 2.960 & 0.001 & 0.012 & -0.125 & 2.148 \\
\hline \multirow[t]{2}{*}{ Brazil } & ETF & 0.001 & 0.013 & -0.114 & 1.237 & 0.002 & 0.016 & -0.168 & 1.509 \\
\hline & Index & 0.001 & 0.012 & -0.154 & 0.912 & 0.002 & 0.016 & -0.103 & 1.198 \\
\hline \multirow[t]{2}{*}{ Canada } & ETF & 0.000 & 0.006 & -0.641 & 1.762 & 0.001 & 0.010 & -0.208 & 3.689 \\
\hline & Index & 0.000 & 0.006 & -0.513 & 2.737 & 0.001 & 0.010 & -0.298 & 3.876 \\
\hline \multirow[t]{2}{*}{ China } & ETF & 0.000 & 0.013 & 0.071 & 3.582 & 0.001 & 0.013 & 0.707 & 6.803 \\
\hline & Index & 0.000 & 0.012 & -0.046 & 2.492 & 0.001 & 0.012 & 0.162 & 3.519 \\
\hline \multirow[t]{2}{*}{ Eurozone } & ETF & 0.000 & 0.008 & -0.618 & 1.474 & 0.001 & 0.014 & 0.241 & 3.932 \\
\hline & Index & 0.000 & 0.008 & -0.513 & 1.523 & 0.001 & 0.014 & 0.080 & 2.947 \\
\hline \multirow[t]{2}{*}{ France } & ETF & 0.000 & 0.009 & -0.744 & 2.196 & 0.001 & 0.014 & 0.210 & 3.672 \\
\hline & Index & 0.000 & 0.008 & -0.557 & 1.683 & 0.001 & 0.014 & 0.195 & 3.887 \\
\hline \multirow[t]{2}{*}{ Germany } & ETF & 0.000 & 0.009 & -0.506 & 1.192 & 0.002 & 0.014 & 0.099 & 3.884 \\
\hline & Index & 0.000 & 0.009 & -0.407 & 1.117 & 0.001 & 0.015 & 0.010 & 2.576 \\
\hline \multirow{2}{*}{$\begin{array}{l}\text { Hong } \\
\text { Kong }\end{array}$} & ETF & 0.000 & 0.011 & -0.296 & 1.356 & 0.001 & 0.013 & -0.592 & 2.045 \\
\hline & Index & 0.000 & 0.011 & -0.345 & 1.512 & 0.001 & 0.013 & -0.496 & 1.860 \\
\hline \multirow[t]{2}{*}{ India } & ETF & 0.000 & 0.008 & 0.494 & 3.816 & 0.002 & 0.012 & -0.193 & 4.210 \\
\hline & Index & 0.000 & 0.008 & 0.464 & 3.791 & 0.002 & 0.014 & 0.157 & 6.068 \\
\hline \multirow[t]{2}{*}{ Japan } & ETF & 0.000 & 0.010 & -0.497 & 3.693 & 0.001 & 0.011 & -0.147 & 1.217 \\
\hline & Index & 0.000 & 0.010 & -0.475 & 3.988 & 0.001 & 0.011 & -0.046 & 1.275 \\
\hline \multirow{2}{*}{$\begin{array}{l}\text { New Zea- } \\
\text { land }\end{array}$} & ETF & 0.000 & 0.006 & -0.521 & 1.735 & 0.001 & 0.009 & 0.377 & 1.054 \\
\hline & Index & 0.000 & 0.005 & -0.619 & 3.125 & 0.001 & 0.008 & 0.200 & 1.002 \\
\hline \multirow{2}{*}{$\begin{array}{l}\text { South } \\
\text { Korea }\end{array}$} & ETF & 0.000 & 0.009 & -0.547 & 2.023 & 0.002 & 0.014 & -0.119 & 2.069 \\
\hline & Index & 0.000 & 0.009 & -0.580 & 2.113 & 0.002 & 0.014 & -0.160 & 1.860 \\
\hline \multirow[t]{2}{*}{ Taiwan } & ETF & 0.000 & 0.009 & -1.518 & 10.212 & 0.002 & 0.011 & 0.051 & 2.100 \\
\hline & Index & 0.000 & 0.010 & -1.177 & 7.296 & 0.002 & 0.012 & -0.019 & 1.270 \\
\hline \multirow[t]{2}{*}{ UK } & ETF & 0.000 & 0.008 & -0.352 & 1.560 & 0.001 & 0.013 & -0.136 & 1.536 \\
\hline & Index & 0.000 & 0.008 & -0.404 & 1.653 & 0.001 & 0.013 & -0.088 & 1.386 \\
\hline \multirow[t]{2}{*}{ USA } & ETF & 0.000 & 0.009 & -0.616 & 3.965 & 0.002 & 0.013 & -0.396 & 4.410 \\
\hline & Index & 0.000 & 0.009 & -0.630 & 3.928 & 0.002 & 0.013 & -0.352 & 4.755 \\
\hline
\end{tabular}

\section{Results}

The entropy based efficiency estimation results are presented and discussed at two levels. First, a full sample (static) analysis of the informational efficiency of each ETF and its underlying index is undertaken. Next, COVID-19 outbreak's impact on the dynamic informational efficiency is estimated using a rolling window approach. 


\subsection{Full sample informational efficiency}

Figure 1 shows informational efficiency estimates for the static sample across all the chosen time scales $(\tau=1, \ldots, 30)$. The drop in $I_{I M E}(\tau)$ for increasing values of $\tau$ across all markets is due to decline in underlying entropy as time scale $(\tau)$ increases. This is due to the reduction of "pattern richness" after filtering the time series using the coarse-graining procedure. These findings are in line with prior studies using entropy methods on various markets (Ortiz-Cruz et al. 2012; Wang and Wang 2021).

A comparison of various panels lead to novel findings. We see that the efficiency index of ETFs and indices from USA and Canada are consistently lower than other markets. On the other hand, ETFs and indices from China, Hong Kong, Taiwan and Japan are seen to be more efficient than remaining markets. We also see that in many cases, the efficiency levels of ETFs do not exactly mimic the level of efficiency of the underlying indices.

\subsection{Dynamic informational efficiency}

A rolling window methodology is used to measure the time-varying efficiency for both the ETFs and their underlying indices. Here, we relax the implicit assumption that the efficiency level is constant over time. As the economic environment evolves over time and as unforeseen shocks like covid-19 pandemic unfold, a rolling window analysis helps us examine the time varying nature of efficiency. Should the efficiency levels be stable over time, then the rolling window estimates would not vary much. On the other hand, any instability or change in the efficiency level over time will be captured by the dynamic rolling window estimates (Zivot and Wang 2003). In line with precedence in literature, we use the rolling window length of 252 days (Wang and Wang 2021). The rolling window analysis begins with the estimation of efficiency index, $I_{I M E}(\tau)$ for the first window period of 252 daily log return values. Then the window is moved forward based on the chosen value of $\tau$. For $\tau=1$, the rolling windows moves forward a day. Figure 2 shows the daily $(\tau=1)$ informational efficiency plots of all ETFs and their underlying indices.

Quite a few observations stand out. First, as expected, the efficiency drops during Feb-March 2020 when COVID-19 spread rapidly across the world. In addition, more interesting findings can also be gleaned. The fall in informational efficiency was the most for ETFs and indices from Canada and USA, while the ETFs and indices from China, Hong Kong, Japan, South Korea and Taiwan saw the least drop. Another notable observation is that the level of informational efficiency of several developed markets are lower than other cases even in the pre-covid days. Moreover, we see that in several cases, the efficiency plots of the ETFs and their indices do not coincide, especially after the march $2020 \mathrm{crash}$ (Australia, Germany, New Zealand and Taiwan). An encouraging observation is that the level of informational efficiency is seen to increase towards the end of the plots, suggesting that market imperfections have reduced over time. 
Table 3 ETF pre-crash efficiency

\begin{tabular}{ll}
\hline ETF & pre-crash $I_{I M E}$ \\
\hline Brazil & 0.894 \\
Hong Kong & 0.883 \\
South Korea & 0.881 \\
UK & 0.867 \\
New Zealand & 0.856 \\
China & 0.847 \\
Australia & 0.846 \\
Canada & 0.841 \\
India & 0.832 \\
Germany & 0.823 \\
Taiwan & 0.794 \\
France & 0.782 \\
Japan & 0.769 \\
Eurozone & 0.768 \\
USA & 0.702 \\
\hline
\end{tabular}

Average of rolling $I_{I M E}$ values from January 01, 2018 to January 31, 2020

\subsection{Comparison}

We compare the relative efficiency of ETFs and the Indices based on the average of rolling efficiency index values before and after the Covid-induced market crash (Feb-Mar 2020). While the covid-induced market crash impacted all ETFs and their underlying indices, the magnitude of impact was different for different countries. Tables 3 and 4 show the average efficiency index values for all the ETFs. Of all the ETFs considered for this study, the ETFs of Brazil and Canada appear to be the most affected by the covid induced market crash. Also, the USA based ETF was among the relatively least efficient ones in both the timelines.

Similarly, Tables 5 and 6 show the average efficiency index values for all the underlying indices. While the results for the indices are qualitatively similar to their ETFs, a few notable exceptions stand out. The Indian equity Index shows a higher level of relative efficiency than its ETF, especially in the pre-crash timeline. For the post-crash timelines, indices of Germany, Eurozone and New Zealand were relatively more efficient than their ETFs.

A visual illustration of the findings pertaining to Tables 3 to 6 is made available in Fig. 2, which shows the dynamic nature of informational efficiency of all the ETFs and indices.

A potential factor behind the relative efficiency of ETFs in the pre-crash timeline could be the differential taxation rules in various geographies. ${ }^{1}$ It may be noted that ETFs generate capital gains during rebalancing or creation / redemption process.

\footnotetext{
${ }^{1}$ We thank the anonymous reviewer for highlighting this aspect.
} 
Table 4 ETF post-crash efficiency

\begin{tabular}{ll}
\hline ETF & post-crash $I_{I M E}$ \\
\hline Hong Kong & 0.794 \\
China & 0.714 \\
Taiwan & 0.690 \\
South Korea & 0.681 \\
Japan & 0.671 \\
UK & 0.587 \\
Australia & 0.578 \\
Brazil & 0.540 \\
India & 0.532 \\
New Zealand & 0.528 \\
France & 0.523 \\
Germany & 0.484 \\
Eurozone & 0.451 \\
USA & 0.417 \\
Canada & 0.310
\end{tabular}

Average of rolling $I_{I M E}$ values from April 01, 2020 to April 30, 2021

Table 5 Index pre-crash efficiency

\begin{tabular}{ll}
\hline Equity Index & pre-crash $I_{I M E}$ \\
\hline Brazil & 0.922 \\
Hong Kong & 0.895 \\
China & 0.876 \\
India & 0.871 \\
South Korea & 0.870 \\
New Zealand & 0.864 \\
UK & 0.850 \\
Australia & 0.847 \\
Taiwan & 0.834 \\
Canada & 0.829 \\
Germany & 0.814 \\
France & 0.796 \\
Eurozone & 0.780 \\
Japan & 0.762 \\
USA & 0.706 \\
\hline Averag of
\end{tabular}

Average of rolling $I_{I M E}$ values from January 01, 2018 to January 31, 2020

While ETF sponsors in developed economies are liable to pay capital gains taxes, such capital gains are not taxed in many emerging economies such as India and China (Shadforth et al. 2020; Ramachandran and Saha 2020). Further, emerging markets across the globe offer tax friendly policies towards non-resident institutional investors (Blitz et al. 2012). On the other hand, investors in developed markets resort 
Table 6 Index post-crash efficiency

\begin{tabular}{ll}
\hline Equity Index & post-crash $I_{I M E}$ \\
\hline Hong Kong & 0.803 \\
Taiwan & 0.745 \\
China & 0.726 \\
South Korea & 0.675 \\
Japan & 0.661 \\
UK & 0.586 \\
New Zealand & 0.570 \\
Germany & 0.552 \\
Australia & 0.539 \\
Brazil & 0.533 \\
Eurozone & 0.521 \\
India & 0.517 \\
France & 0.517 \\
USA & 0.402 \\
Canada & 0.311 \\
\hline
\end{tabular}

Average of rolling $I_{I M E}$ values from April 01, 2020 to April 30, 2021

to trading ETFs so as to take advantage of various taxation loopholes such as tax loss harvesting and redemption in kind (Bouchey et al. 2016; Mider et al. 2019). Consequently, it is very likely that the relative ranking of ETFs is a function of differential taxation and regulatory environment across geographies. The findings of this study in-connection with relative efficiency levels are, to some extent, in alignment with Morningstar's recent Regulation and Taxation Scorecard for various economies (Pettit et al. 2020).

\section{Conclusion}

This study analyses the informational efficiency of domestic ETFs and their underlying indices across various markets during the COVID-19 outbreak. We estimate informational efficiency using a refined multiscale entropy-based efficiency index. This methodology is used to measure static and dynamic efficiency of the ETFs and their underlying indices. The takeaways from this study are as follows. First, COVID-19 led to a decline in efficiency of all ETFs and their indices. This inference is based on the rolling window estimations that capture the relative efficiency of ETFs and their underlying indices over time. These findings are in line with literature that have examined the impact of crises on financial markets (Lim et al. 2008; Ortiz-Cruz et al. 2012). Further, the efficiency of ETFs and their indices revert to pre-crash levels since Jan-Feb 2021. This transient deterioration in efficiency levels followed by subsequent reversion of the same is in alignment with Adaptive Market Hypothesis (Lo 2012) and is indicative of agents exhibiting lower rationality during market turbulence. The drop in efficiency during COVID may be attributed to increased fear among investors (Subramaniam and Chakraborty 2021). 


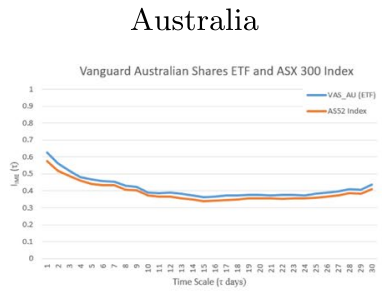

China

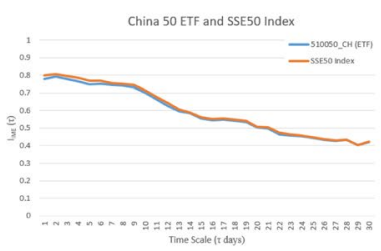

Germany

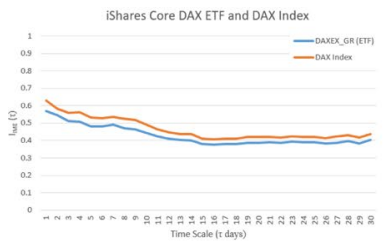

Japan

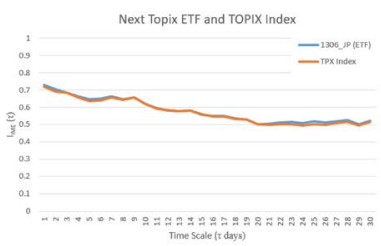

Taiwan

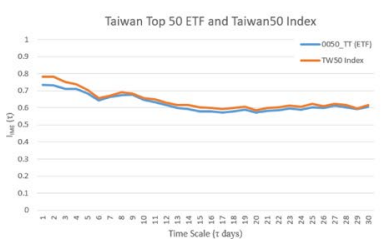

Brazil

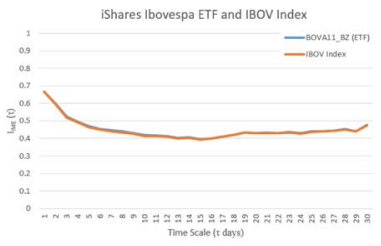

Eurozone

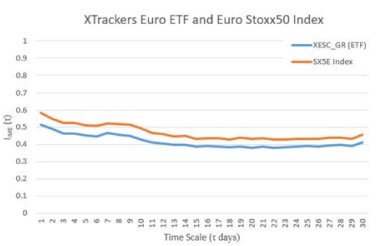

Hong Kong

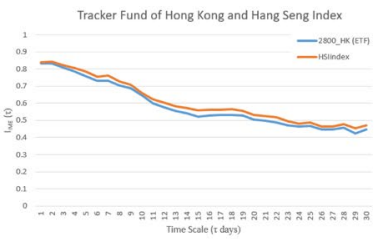

New Zealand

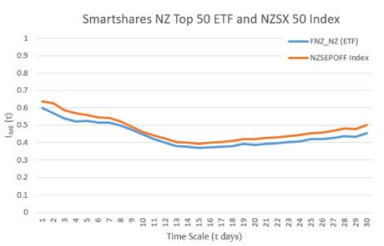

UK

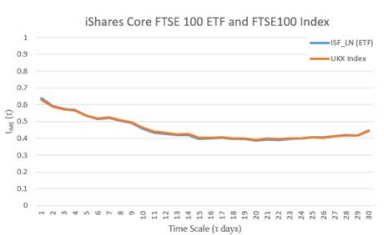

Canada

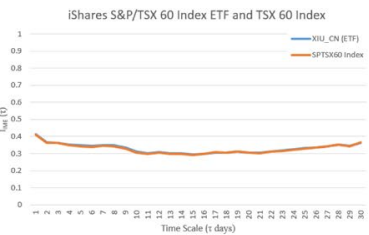

France

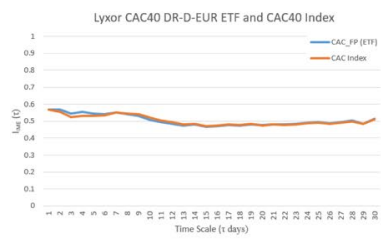

India

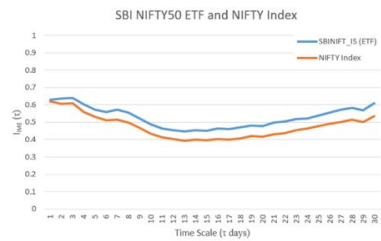

South Korea

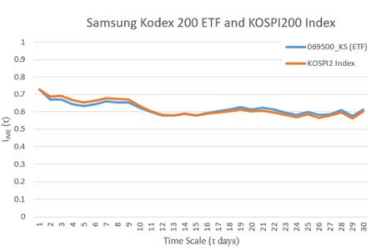

USA

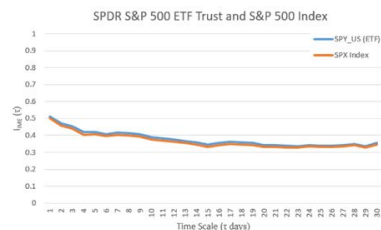

Fig. 1 Static Efficiency plots $\left(I_{I M E}\right.$ across Time Scales, $\left.\tau\right)$

Second, developed markets exhibit relatively lower levels of efficiency than most other emerging markets during the covid-19 induced market crash. Put differently, not all domestic ETFs were equally impacted by the covid-19 crisis. The magnitude 

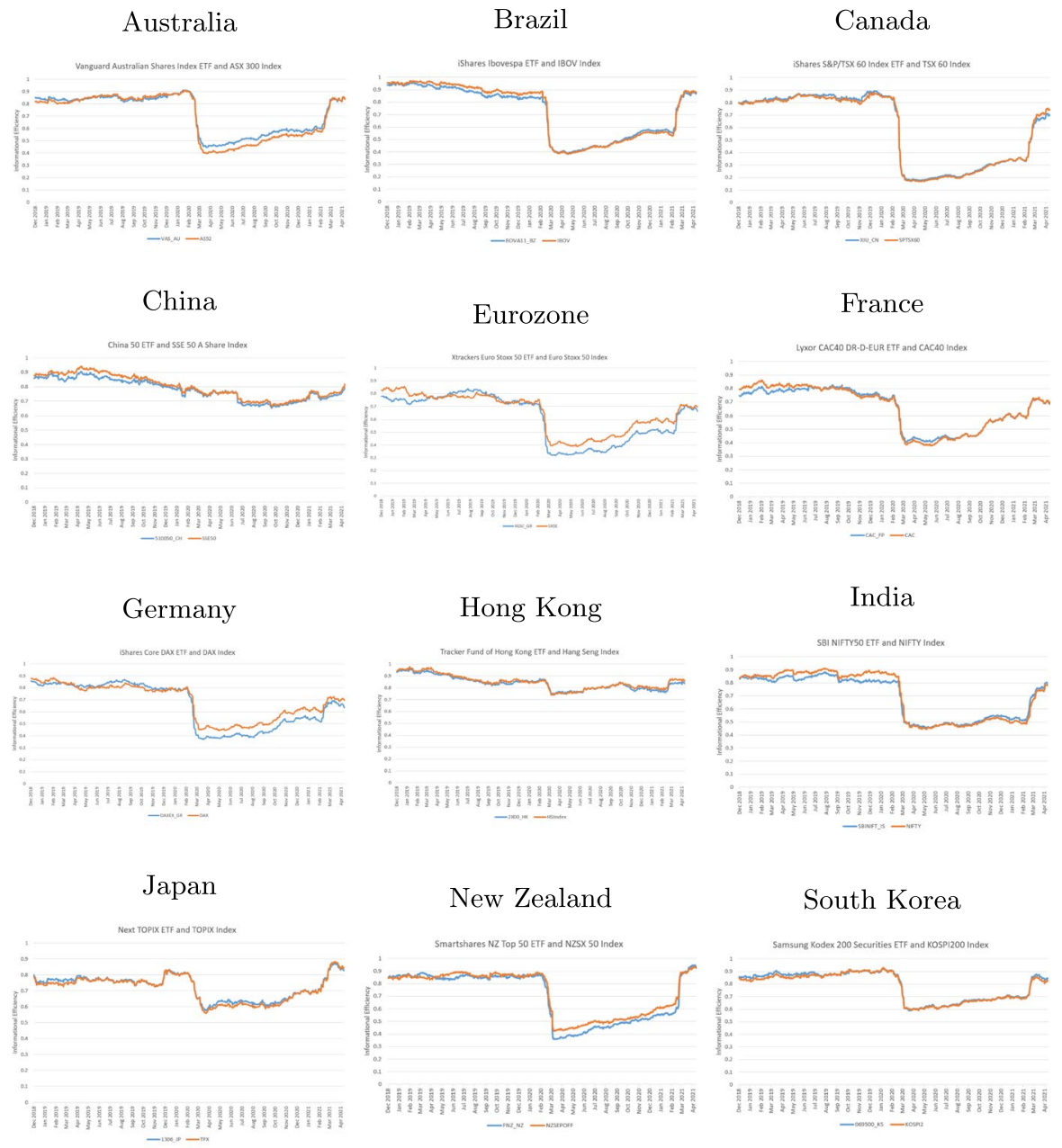

Taiwan

UK

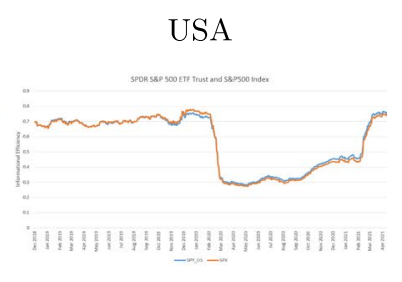

Fig. 2 Dynamic Efficiency plots $\left[I_{I M E}(\tau=1)\right]$ from January 2018 to April 2021

of drop in efficiency could be due to the degree of distrust in governments. For instance, Engelhardt et al. (2021) reported that volatility of equity markets in hightrust countries was significantly lower than low-trust countries during covid. Third, ETFs and indices pertaining to several developed markets were found to be less efficient than their emerging market counterparts even during the pre-covid timeline. As 
stated earlier, we believe that differential taxation on ETFs across the globe may be a contributory factor in this regard. Fourth, our findings indicate that not all domestic ETFs considered for this study exactly mimic the dynamics of the underlying indices. In conclusion, these findings should nudge investors to deal with domestic ETFs on a case-to-case basis.

Acknowledgements We thank participants at the $28^{\text {th }}$ Global Finance Conference 2021 for valuable comments. In addition, we are grateful to the editor and two anonymous reviewers for their constructive comments and suggestions that helped us improve the paper. All remaining errors are ours.

Funding This research received no specific grant from any funding agency in the public, commercial, or not-for-profit sectors.

Data and Code availability The data that support the findings of this study are available from Bloomberg but restrictions apply to the availability of these data, which were used under license for the current study, and so are not publicly available. Data are however available from the authors upon reasonable request and with permission of Bloomberg and the source code for analysis associated with the current submission is available at https://doi.org/10.1007/s11517-017-1647-5.

\section{Declarations}

Conflicts of interest The authors declare that they have no conflict of interest.

\section{References}

Alvarez-Ramirez J, Rodriguez E, Alvarez J (2012) A multiscale entropy approach for market efficiency. International Review of Financial Analysis 21:64-69. https://doi.org/10.1016/j.irfa.2011.12.001

Azami H, Fernández A, Escudero J (2017) Refined multiscale fuzzy entropy based on standard deviation for biomedical signal analysis. Medical \& Biological Engineering \& Computing 55(11):2037-2052. https://doi.org/10.1007/s11517-017-1647-5

Blitz D, Huij J, Swinkels L (2012) The performance of european index funds and exchange-traded funds. European Financial Management 18(4):649-662. https://doi.org/10.1111/j.1468-036X.2010. 00550.x

Bouchey P, Brunel JL, Li T (2016) The role of ETFs in active tax management. The Journal of Wealth Management 19(3):75-86. https://doi.org/10.3905/jwm.2016.19.3.075

Caporale GM, Gil-Alana LA, Martin-Valmayor M (2020) Persistence in the market risk premium: evidence across countries. J Econo Finan: 1-15. https://doi.org/10.1007/s12197-020-09519-3

Engelhardt N, Krause M, Neukirchen D et al (2021) Trust and stock market volatility during the covid-19 crisis. Finance Research Letters 38:101873. https://doi.org/10.1016/j.frl.2020.101873

Fama EF (1965) Random walks in stock market prices. Financial Analysts Journal 21(5):55-59. https:// doi.org/10.2469/faj.v51.n1.1861

Gulko L (1999) The entropic market hypothesis. International Journal of theoretical and applied finance 2(03):293-329. https://doi.org/10.1142/S0219024999000170

Huang S, O'Hara M, Zhong Z (2021) Innovation and informed trading: Evidence from industry etfs. The Review of Financial Studies 34(3):1280-1316. https://doi.org/10.1093/rfs/hhaa077

Lim KP, Brooks RD, Kim JH (2008) Financial crisis and stock market efficiency: Empirical evidence from asian countries. International Review of Financial Analysis 17(3):571-591. https://doi.org/10. 1016/j.irfa.2007.03.001

Lo AW (2012) Adaptive markets and the new world order. Financial Analysts Journal 68(2):18-29. https://doi.org/10.2469/faj.v68.n2.6

Mider ZR, Evans R, Wilson C, et al (2019) The ETF tax dodge is wall street's 'dirty little secret'. Tech. rep., Bloomberg. Available at https://www.bloomberg.com/graphics/2019-etf-tax-dodge-lets-inves tors-save-big. Accessed 20 Oct 2021 
Ortiz-Cruz A, Rodriguez E, Ibarra-Valdez C et al (2012) Efficiency of crude oil markets: Evidences from informational entropy analysis. Energy Policy 41:365-373. https://doi.org/10.1016/j.enpol.2011.10. 057

Pettit A, Szapiro A, Kennaway G, et al (2020) Global investor experience study: Regulation and taxation. Tech. rep., Morningstar Research. Available at https://www.morningstar.com/content/dam/marke ting/shared/pdfs/Research/GFIE_2020_FINAL.pdf. Accessed 20 Oct 2021

Ramachandran S, Saha N (2020) A report on the indian exchange traded funds (ETF) industry. Tech. rep., CFA Institute. Available at https://www.moneymanagementindia.net/wp-content/uploads/A-Reporton-the-Indian-Exchange-Traded-Funds-ETF-Industry-by-CFA-Society-India.pdf. Accessed 20 Oct 2021

Saha K, Madhavan V, Chandrashekhar G (2020) Relative efficiency of equity ETFs: an adaptive market hypothesis perspective. Appl Econ Lett: 1-6. https://doi.org/10.1080/13504851.2020.1804045

Shadforth E, Narula R, So L, et al (2020) ETF taxation report for investors, mainland china. Tech. rep., EY Research. Available at https://www.hkex.com.hk/-/media/HKEX-Market/Products/Securities/ Exchange-Traded-Products/Launch/ETF-Tax-Report-2020-Oct_Mainland-China.pdf. Accessed 20 Oct 2021

Subramaniam S, Chakraborty M (2021) Covid-19 fear index: does it matter for stock market returns? Review of Behavioral Finance 13(1):40-50. https://doi.org/10.1108/RBF-08-2020-0215

Wang J, Wang X (2021) Covid-19 and financial market efficiency: Evidence from an entropy-based analysis. Finan Res Lett: 101888. https://doi.org/10.1016/j.frl.2020.101888

Xu L, Yin X (2017) Does ETF trading affect the efficiency of the underlying index? International Review of Financial Analysis 51:82-101. https://doi.org/10.1016/j.irfa.2017.02.009

$\mathrm{Xu} \mathrm{L}$, Yin X, Zhao J (2019) The sidedness and informativeness of ETF trading and the market efficiency of their underlying indexes. Pacific-Basin Finance Journal 58(101):217. https://doi.org/10.1016/j. pacfin.2019.101217

Zhu X, Bao S (2019) Multifractality, efficiency and cross-correlations analysis of the american ETF market: Evidence from SPY, DIA and QQQ. Physica A: Statistical Mechanics and its Applications 533:121942. https://doi.org/10.1016/j.physa.2019.121942

Zivot E, Wang J (2003) Rolling analysis of time series. In: Modeling financial time series with S-Plus®. Springer, pp 299-346. https://doi.org/10.1007/978-0-387-21763-5_9 